\title{
Cyber-Physical System and Its Application in Textile and Chemical Fiber Enterprises
}

\author{
Hui Ding, Chenggang $\mathrm{Li}^{*}$ \\ The Business Department, Beijing Institute of Fashion Technology, Beijing, China \\ Email: ${ }^{* 317877593 @ q q . c o m ~}$
}

How to cite this paper: Ding, $\mathrm{H}$. and $\mathrm{Li}$, C.G. (2017) Cyber-Physical System and Its Application in Textile and Chemical Fiber Enterprises. Open Journal of Social Sciences, 5, 352-360.

https://doi.org/10.4236/jss.2017.510029

Received: October 17, 2017

Accepted: November 18, 2017

Published: November 21, 2017

\begin{abstract}
Cyber-Physical system (referred to as CPS) is based on the physical environment perception, the use of sensor, wireless communication network and computer system to detect and control the machine technology. It is a modern physics system with a set of computing, communication and control as one. Textile and chemical fiber industry as China's traditional pillar industries of the national economy, in the context of the new normal economy, is of great significance in the transformation and upgrading for boosting industrial development, enhance the competitiveness of the industry at home and abroad. This paper takes Zhejiang xinfengming group as an example, describing it with the help of CPS technology upgrading in production technology, process and enterprise management. The production capacity, management ability and competitiveness of the industry obtain great improvement, making great significance to the traditional textile industry transformation and upgrading.
\end{abstract}

\section{Keywords}

Cyber-Physical System, Transformation and Upgrading, Operation Mode

\section{Introduction}

The concept of information physics system was first proposed by Helen Gill of the National Science Foundation of the United States. There are many definitions for the CPS. The most representative one is Lee's in 2008: he defines it as a close integration of a series of calculation process and physical process components. It will monitor a physical entity by computing the core operation, also with the help of physical network and computing components to achieve the sensing and control of the environment [1].

In fact, the physical information system is currently the most advanced a set of modern physics system [2]. It is the upgrade version of the networking tech- 
nology. It is based on the physical environment perception, the use of sensor, wireless communication network and computer system to detect and control the machine technology. It is a modern physics system with a set of computing, communication and control as one.

On the one hand, it can carry out information feedback according to the physical surroundings; on the other hand, according to the information received, it can make independent decisions finally through the implementation of controller control machine.

The ultimate goal of CPS is to complete the program independently and the global Internet docking services to find the optimal solution, build a control, trust and independent network system, realize the perfect integration of the information world and the physical world.

The key part relates to the manufacturing system of CPS technology has five aspects: internal sensor networks and system network equipment, control construction method, network manufacturing system of universal control method in distributed intelligent information acquisition and processing method and system. The whole system framework involves three aspects: feeling layer, communication layer and decision layer [3].

The feeling layer is the level that the machine can feel the physical world. It consists of multiple feeling nodes. On the one hand, the physical properties of sensors can perceive the surrounding physical environment and facilities, such as the environment temperature, humidity, running distance, device stress, or some special time, such as the damage of equipment needs to be updated with new tools. On the other hand, according to the control command information received by the decision layer, the corresponding execution of the target is carried out by the execution controller of the sensing layer, such as replacing the damaged parts and opening a production task.

The communication layer is the level combines network connection and the calculation, it can interconnect communication base stations and network nodes through the wired network, WiFi, ZigBee, 3G/4G, and connect information processing server together as to accurate information transmission data real-time transmission, the correct treatment and command. The communication layer is the intermediate hub link of the whole CPS system, and the information, data and command will be sent through this link. The stable operation of this link plays a vital role in the whole system function [4].

The decision layer is equivalent to the human brain, which is the terminal of CPS to make information processing and take corresponding reaction measures to the surrounding environment change, including simulation control center and decision control unit [5]. Program for changes in the physical environment is completed in the simulation control center, the main function of the system of internal control center simulation is to build a virtual simulation environment of control, all kinds of reality may occur based on the possible consequences of using virtual simulation procedures, and formulate corresponding solutions, solutions to generate initial. Combining theory with practice, through the perception 
of the physical environment of information uploaded to the decision-making level to validate and perfect solution, combining the simulation through online and offline simulation, the formation of a credible solution.

The decision is to directly control unit operation function. The system can also provide a visual interactive program for manual operation, targeting treatment system to deal with the problem, to avoid the occurrence of fault causing irreparable damage [6].

\section{The Application}

In recent years, our country began to strengthen the importance and application of Cyber-physical system. As China's traditional industry economic growth appeared in the new normal, to maintain the sustainable development of the economy to the future, we must change the mode of economic development, adapt to the development trend of the times. The State Council Premier Li Keqiang put forward the "2025" and "two Chinese manufacturing integration" and "supply side" reform, paying attention to product supply the improvement, provide better service for the people. China will strengthen the application of CPS in the field of industrial production. Using CPS Technology (industrial manufacturing, aviation, medical etc.), to change the physical entity from centralized to decentralized control mode, realizing intelligent development of manufacturing industry. To create a more intelligent way of life and production through the manufacturing of global technical support.

Textile industry is the pillar industry of our national economy, the textile industrial added value accounted for $5.6 \%$ of national industry. Industrial chemical textile fiber accounted for the total share of more than $70 \%$, and it resolved the problem of China's hundreds of millions of people dress. The current has entered a new stage of development of textile and chemical fiber industry. It is facing many problems and challenges: both domestic and foreign environmental impact and the progressive development of perplexing problems. The industry itself formed in the development process of management and innovation is behind the problem. In order to promote the production and management mode transformation of textile and chemical fiber industry, strengthen the reform of the supply side, now part of the enterprise in the industry has taken the lead in the introduction of advanced production technology (such as CPS technology and management experience, etc.) It applied to the enterprise production workshop, the processing process and standardizes management, to optimize the overall efficiency of the enterprise upgrade.

Xin Feng Ming Group is the most typical enterprise in 2017. The group is listed on the A shares, the enterprise is the only one focusing on the domestic large-scale filament manufacturing enterprises in pyrethroid. In the homogenization of the industry price competition of the Red Sea, it dares to focus on the future introduction of intelligent manufacturing technology, through collective leadership attention and staff skills training, apply the CPS technique to the 
production and management, increasing the production scale, standardized production processes and improving product quality and competitiveness to avoid in the "Red Sea" in the competition.

\subsection{The Reason of Application}

First, owing to deal with the rising production cost of enterprise. Chemical fiber industry in China has gone through a long time. It is in the textile and garment industry upstream of the industrial chain, as a traditional manufacturing industry. The enterprise has many aspects in the production process. On the one hand, chemical fiber enterprises has many positions of labor intense such as products, handling, packaging and other aspects of the pocket, which all need to be done manually. On the other hand, the traditional filament production workshop environment is under terrible conditions, such as product winding of large noise, plant internal temperature higher. They are easy to suffer from occupation disease, such as lumbar disc herniation, so the staff turnover rate is high, enterprises can only be used to retain and hire workers a raise. Compared with South Korea, Indonesia, Taiwan and other places, the degree of automation in production in China is low. Besides, with high salaries, it result in competition with foreign enterprises. The labor costs of domestic products is at a disadvantage, which makes the whole competitiveness of products also declined.

Second, it is increase product quality and streamlines production. As a filament Xin Feng Ming Group manufacturing enterprises, it has three series of products: POY, FDY and DTY. Enterprises can realize automatic control of polymerization and spinning in two steps, but the product in extinguishers, handling, labeling, packaging and warehousing or relying on the manual operation is performed. This operation is easy to cause the product damage, mixed bag, mixed problem, once a problem with the cake was used as warp weave fabric, it may cause millions of dollars in losses. Filament enterprise customers are generally long-term customers, once the problem is not settled very well, it will directly affect the sales of the products, so the stability of product quality is the source of the filament of enterprise development. Quality control is a very important task to control enterprise filament.

Finally, there are strengthening management and enhancing market competitiveness. On the one hand, because of the chemical fiber enterprise solution spinning equipment has particularity, if it is in the maintenance period of non accident parking equipment, it will lead to the whole production line production, and the losses could reach millions of dollars. On the other hand, Xin Feng Ming Group product variety, daily output is up to about 400,000 , in the process of product labeling and logistics, if it is still using manual registration and statistics, product information; it is difficult to meet the customers for the products of the real-time and accuracy requirements. Only a large amount of data is still rely in modern information technology, it can achieve the automation of information flow and logistics. 


\subsection{The Application in Production Process of Enterprises}

In the backgroud of new economic norm, rising labor costs, Xin Feng Ming Group actively carries out the transformation and upgrading of hardware and software system, and it works with Italy Race Dragon Company jointly to develop CPS technology, and it CPS architecture of the robot system, network system. The sensor system is applied to the production of filament winding, extinguishers, marking and packaging warehousing. CPS software system for the enterprise software is from SIEMENS, which learned the application experience of domestic and foreign enterprises; the system has the following features: hierarchical control; data transmission speed; multi touch; wired and wireless interactive transmission; independent and artificial control combination. The CPS architecture consists of three layers (induction layer, communication layer, decision-making layer). Induction layer transmits data to the information database by wired or wireless networks. The decision layer analyses the data collected, processing and sending a order according to the solution predefined to deal with the machine environment changes. The decision procedure is independent of each other to avoid the influence of the local operation to the whole. After the production process reengineered, such as a production line of only 8 people which have been cut to 3 people. 75 production lines of Xin Feng Ming Group can be reduced by 375 in total. So the operation of the whole system, not only reduces the labor cost and error loss, but also realizes the whole production process (from the winding to the storage of information and Automation), improving the product quality and the management level of enterprises. At the same time, it provides the most valuable production data in the era of big data, and provides reliable information resources for the fine management of enterprises in the future.

The specific application is, in production process, according to the production process of chemical fiber spinning enterprises in the winding barrel, falling cake weight detection, bagging, printing paper tube label, bagging and palletizing, strapping, stretch film and storage procedures and other processes, the traditional enterprises are using artificial, automation technology which is not advanced enough. It is the characteristics of the traditional textile industry. When the CPS technology is applied to every link of the production process, it implements the automatic winder, weight detection, two-dimensional code information identification, robot handling warehousing. This method has changed the characteristics of the traditional textile factory workshop, and liberated labor resources, greatly improving production efficiency. Modern production process ensures the quality of production and management level of ascension.

In product management, the link between production and sales is the product management. Because of the characteristics of the real economy, the product is not directly from the factory to the seller, most of which needs the product inventory. Inventory stock, cycle, management norms are essential to the cash flow operation of enterprises. Xin Feng Ming Group using CPS technology to set up 
the product data management platform, according to the quantity and sales of inventory products, to analyse product life cycle. These analysis data can provide the basis for the formulation of enterprise production plan, making inventory early warning mechanism, which can avoid causing excessive or less inventory to ensure the group inventory maintain the lowest level of the industry.

In financial system, sales are an important part of the value of enterprises. The ultimate goal of the enterprise is to create profits. The modernization of the production process can bring sales information transparency. The application of CPS technology in the financial system reflected in the sales data platform, customer service service management platform. The company uses the direct connection Kingdee financial system, making ERP and CPS combine together, automatically generates vouchers and tax billing system. The enterprise daily output is staggering; there are also many group affiliated enterprises. Using fewer people to manage the massive product sales have been leading issue of enterprises. The sales data platform developed by CPS, can be a real-time monitoring of sales data of each subsidiary (category, quantity, price, object, area), and transparent the data which will help it prevent the financial corruption chaos, realizing the healthy operation.

In staff management, because the traditional textile enterprise is a labor-intensive enterprise, the management and assessment of employees has always been a big problem. When the application of CPS technology is used to all links of products, it can be very convenient for the assessment of the staff performance, and will be published in the internal network. Besides, responsibility system can make the employee performance and salary connect with promotion, stimulating staff's innovative spirit and sense of responsibility. Transparent enterprise performance appraisal and salary can improve employee's loyalty and get the lowest level staff turnover in the industry, making the enterprises and individuals, sharing social development interests, realizing the sustainable development of enterprises.

\subsection{The Application Effect}

The application effect is reducing production cost. Xin Feng Ming Group upgraded under the CPS system framework and introduced automation of robots in the production process. The introduction of robots, compared to manual production, has undergone a qualitative change in terms of work time, work efficiency and work strength. Nowadays, it can be 24 hours of uninterrupted line of work in the production workshop. Automatic production line mode of enterprises is the one of the key technological achievements in 2013 National Science and technology progress prize two project "super high-capacity, efficient, flexible and differential polyester filament complete engineering technology development". So it has great progress in the rate of qualified products and flexible efficiency. In a short period of time, the introduction of robots is more expensive than labor cost, but in the long term, labour resources will be released by the robot, and then employees pay more attention to improving their skills and de- 
veloping production management. Finally, it has become inevitable in the reduction of production costs.

It also improve the enthusiasm of employees, reduce the turnover rate. The turnover rate dropped from $7.22 \%$ in 2013 to $3.8 \%$ in 2014 and continued to decline to $2.3 \%$ in 2015. On the one hand, although the introduction of CPS system technology extruded the traditional jobs in a certain extent, but these workers will be transferred to the company's new production line. The enterprises ensure the target-increasing production without increasing labour, reducing the turnover rate, and then employees need not worry about the risk of being fired. On the other hand, the robot instead of employees for the traditional high-intensity work can effectively ensure the safety of employees. The performance salary is also based on the CPS system, so it has been importantly improved for the enthusiasm of employees.

It enhances the economic benefits of enterprises. The ultimate goal of enterprise transformation and upgrading is to improve the economic efficiency of enterprises. Against a background of rising industry production costs, slumping real economic and entering a New Mormal economy, the application of CPS technology in Xin Feng Ming Group, from the production, inventory management, office mode, financial transparency, staff management and other aspects, enhances the efficiency of enterprises. What's more, the economic efficiency of enterprises is guaranteed by the improvement of efficiency. According to the financial data of Listed Companies in China, in 2014 and 2015 the total profits in enterprises all were more than the industry average, reaching 732 million in 2016. All these have become important influence factors that the Xin Feng Ming Group in 2017 A shares listed.

\section{Conclusion}

\subsection{Application Outlook}

Prospect for application of CPS in chemical fiber industry. Chemical fiber, as new material for the Second Industrial Revolution, its invention, embodies human's wisdom and strength and brings a great help for the solution of the human wearing. It can say that no chemical inventions will be unable to meet the urbanite on the "buy buy buy" behavior in clothing. In the era of "post financial crisis", consumer demand in the world was declining and trade protectionism began to rise. China also turned from rapid growth to medium-high growth in economic development, coupled with the lack of natural resources and increased industry competition, so these have become the difficulties facing the chemical fiber industry in development. The future textile chemical fiber industry is still an important part of China's economy. The development of the industry is related to people's livelihood and the transformation and upgrading of the industry is related to the fate of the industry. When the "Internet plus", "Made in China 2025", "two Chinese manufacturing integration" and other policy measures are put forward, the industry needs to seize the opportunity and seek 
change as a spearhead in the competition of the "Red Sea", upgrading based on the industry.

Xin Feng Ming Group in Zhejiang province, as a leader in chemical fiber industry, dares to be the first--using modern advanced CPS technology to change the traditional production mode. Having undergone creative change in the production, products, finance, office, staff management and other aspects of enterprises, after several years of operation, the group's level of production and management efficiency has been greatly improved, product competitiveness has been strengthened, the production efficiency and the staff's initiative has been enhanced and the enterprise's economic the benefits have been significantly increased. At present, the chemical fiber industry faces dilemma, but the successful experience of application for CPS technology in Xin Feng Ming Group provides referential experience for the transformation and upgrading of other enterprises in the industry. CPS, as the advanced modern physics system now, is applied to textile chemical fiber enterprises lean production, inventory management, financial transparency, employee performance management, it will bring innovative changes, and even the industry will also be full of new vitality.

\subsection{Development Proposals}

First, it's to breaking through the inherent development model. The model of traditional textile chemical fiber industry mainly relies on labor and resources input, which is an extensive production model. It is not only the low production efficiency, but also serious environmental pollution. Transformation and upgrading is to change the development model, apply for modern advanced technology and management experience to break through the original development model. It is transferred from incremental development in the original and rigid standard model to the disruptive innovation breaking through the original mode.

Second, it's necessary to know that innovation is not a simple addition. Transformation and upgrading is not a simple addition of advanced technology, management experience, advanced equipment, financial and material resources. But under the reasonable rules, on the basis of being respect for objective laws, we explore the links between the elements, optimize the combination of various elements, make the whole play the greatest advantage.

Finally, it's important that the company leader must to improve the sense of innovation. According to the theory of management innovation, whether the enterprise can complete the internal innovation (production, management and technological innovation) depends largely on the transformation of manager's thought. Enterprise managers are the core and the brain of the internal operation enterprise and have the greatest influence on the direction of the operation enterprise. Therefore, the transformation and upgrading of enterprises need manager's thinking change and responsibility awareness and social awareness are important factors for the future development of enterprises. 


\section{Acknowledgements}

Corresponding author is Chenggang LI. This work is supported by BIFT Postgraduate Innovative Research Project in 2017 (NO. 120301990122/007); The Project Funds for postgraduate thesis of Beijing Institute of Fashion Technology in 2017 (NO. 110501990112); The General Project of Science Program of Beijing Education Commission in 2017 (NO. AL2017-13); the General Project of Practice Teaching Team of Beijing Institute of Fashion Technology in 2016 (NO. JPJC-1608).

\section{References}

[1] Baheti, R. and Gill, H. (2011) Cyber-Physical Systems. The Impact of Control Technology, 2011, 161-166.

[2] Christophe, T. and Chen, Y.Q. (2009) Optimal Mobile Actuator/Sensor Network Motion Strategy for Parameter Estimation in a Class of Cyber Physical System. Proceeding of the American Control Conference, 2009, 367-372.

[3] Wang, P., Zhong, J. and Xie, L.L. (2011) Cyber-Phycial Systems: A Survey. Acta Automatica Sinica, 37, 1157-1166.

[4] Quadri, Imran, Bagnato, Alessandra, Brosse, Etienne, et al. (2015) Modeling Methodologies for Cyber-Physical Systems: Research Field Study on Inherent and Future Challenges. Ada User Journal.

[5] Obermaisser, R. and Kopetz, H. (2009) Genesys: A Candidate for an Artemis Cross-Domain Reference Architecture for Embedded Systems. Vienna University of Technology, 2009, 5-6.

[6] Yu, Y.C., Hou, T.W. and Chiang, T.C. (2012) Function Seal: Visualized Digital Signature for Electronic Medical Record Systems. Journal of Medical Systems, 36, 3 115-3 121 